\title{
Casearia sylvestris na permeabilidade gástrica à sacarose em equinos submetidos a protocolo de indução de úlcera gástrica
}

\author{
Casearia sylvestris on gastric permeability to sucrose in horses submitted to gastric \\ ulcer induction protocol
}

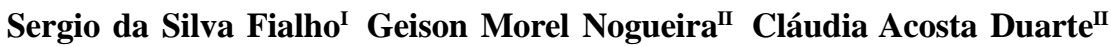 \\ Álvaro de Oliveira Paiva NetoII Delphim da Graça Macoris ${ }^{\text {III }}$
}

\section{RESUMO}

Estudos em animais de laboratório sugerem um efeito antiulcerogênico do extrato de Casearia sylvestris. Esse extrato ainda não foi estudado para a profilaxia e/ou o tratamento de úlceras gástricas em equinos. Para avaliar a influência do extrato de $\boldsymbol{C}$. sylvestris na permeabilidade gástrica à sacarose, seis equinos adultos foram submetidos a modelo de indução de úlceras gástricas. Os animais foram submetidos ao teste de permeabilidade à sacarose antes e ao término do protocolo de restrição alimentar intermitente, para detecção de ulceração gástrica. Durante os sete dias da indução, os animais foram submetidos a tratamentos diários via sondagem nasogástrica com extrato de C. sylvestris $\left(9 \mathrm{mg} \mathrm{kg}^{-1}\right.$ de peso corpóreo) ou veículo (ágar). Após intervalo de 32 dias em piquete, para permitir a cicatrização das úlceras induzidas, cada animal foi submetido novamente ao protocolo de indução de úlcera gástrica, e os tratamentos foram alternados. Dessa forma, cada animal foi submetido a ambos os tratamentos em períodos distintos. A concentração de sacarose na urina foi determinada para cada amostra obtida, por cromatografia líquida de alto desempenho e detecção amperométrica pulsátil. Não foram observadas alterações nos exames clínicos e hemogramas. O tratamento com o extrato de $C$. sylvestris evitou o aumento da concentração de sacarose urinária $(P \leq 0,05)$ quando comparado ao veículo, sugerindo um efeito antiulcerogênico gástrico em equinos. Estudos mais amplos incluindo gastroscopia são necessários para avaliar a possibilidade de usar o extrato para a profilaxia e/ou o tratamento das úlceras gástricas em equinos.

Palavras-chave: equino, Casearia sylvestris, gastrite, estômago.

\section{ABSTRACT}

Studies on laboratory animals suggest an antiulcergonic effect of Casearia sylvestris extract. This extract has not yet been tested for the prophylaxis and/or treatment of gastric ulcers in horses. In order to evaluate the influence of $\boldsymbol{C}$. sylvestris extract on gastric sucrose permeability, six adult horses underwent a protocol of gastric ulcer induction. All animals were submitted to sucrose permeability testing before and at the end of gastric ulcers induction by intermittent feed deprivation, for detection of gastric ulcers. During the seven days of induction, the animals were submitted to daily treatment by nasogastric tubing with $\mathrm{C}$. sylvestris extract $\left(9 \mathrm{mg} \mathrm{kg}^{-1}\right.$ b.w.) or vehicle (Agar). After 32 days of pasture turnout, in order to allow healing of induced ulcers, each animal underwent a second induction protocol, in which treatments were alternated. By this manner, each animal was submitted to both treatments in distinct periods. The urine sucrose concentration was determined for each sample obtained, by high performance liquid chromatography and pulsed amperometric detection. No alterations in clinical examination and hemograms were detected. Treatment with $\boldsymbol{C}$. sylvestris extract avoided the increase on urine sucrose concentration $(P \leq 0.05)$ when compared to the vehicle, suggesting an antiulcer preventive effect for equine gastric ulcers. More extensive studies including gastroscopy are necessary to evaluate the possibility of employing this extract for the prophylaxis and/or treatment of gastric ulcers in horses.

Key words: equine, Casearia sylvestris, gastritis, stomach.

\section{INTRODUÇÃO}

A ulceração gástrica em equinos é uma síndrome de prevalência elevada em potros (MURRAY et al., 1990) e adultos (MURRAY et al., 1996; McCLURE et al., 1999). A síndrome de úlcera gástrica ocorre em 70 a $80 \%$ dos cavalos atletas submetidos a condições intensivas de treinamento e competição (MURRAY et

IDepartamento de Clínica de Grandes Animais (DCGA), Centro de Ciências Rurais (CCR), Universidade Federal de Santa Maria (UFSM), 97105-900, Santa Maria, RS, Brasil. E-mail: ssfialho@smail.ufsm.br. Autor para correspondência.

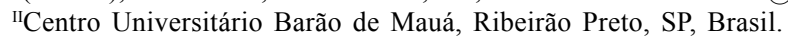

IIIDepartamento de Clínica e Cirurgia, Faculdade de Ciências Agrárias e Veterinárias, UNESP, Jaboticabal, SP, Brasil. 
al., 1996). Os sinais clínicos incluem a diminuição de apetite, a letargia, o bruxismo, as mudanças de comportamento, a perda da condição corpórea e a cólica (MURRAY et al., 1990).

A supressão da acidez gástrica, obtida em equinos por meio do emprego de bloqueadores da bomba de prótons, como, por exemplo, o omeprazole, tem eficácia no tratamento e na prevenção de lesões na mucosa escamosa (ANDREWS et al., 1999). Ainda que efetivos, os bloqueadores da bomba de prótons apresentam um efeito colateral importante, divulgado por ZAVROS et al. (2002). Quando esses pesquisadores trataram ratos com omeprazole por dois meses, observaram que estes desenvolveram inflamação gástrica resultante do crescimento excessivo de outros tipos de bactérias, que não a Helicobacter pylori. Embora considerados seguros, há preocupação a respeito da possibilidade da associação do uso prolongado dos bloqueadores da bomba de prótons com inflamação crônica, câncer e atrofia gástrica em pacientes humanos (RAGHUNATH et al., 2005).

Estudos de SCOTT et al. (2001), empregando a amplificação de DNA-específico para Helicobacter, por meio da reação de polimerase em cadeia, sugeriram que a mucosa gástrica equina é colonizada por espécies de Helicobacter. Estudos sorológicos subsequentes demonstraram que a infecção por Helicobacter em equinos é adquirida ainda nos primeiros meses de vida (SCOTT et al., 2003). Uma das implicações dessas descobertas se refere a mudanças na terapêutica anteriormente preconizada para o tratamento de úlcera gástrica em equinos. A recomendação de antibióticos na terapêutica de equinos que não respondem à medicação antiúlcera tradicional ou que apresentam recorrência frequente de úlceras após tratamento bem-sucedido e que não estão em treinamento, já é uma prática difundida. Em medicina humana, os avanços recentes no tratamento incluem uma variedade de protocolos com diferentes associações de antibióticos de diversas gerações, tendo em vista o surgimento de resistência bacteriana (McLOUGHLIN et al., 2005).

A Casearia sylvestris Swartz é uma árvore pequena, com ocorrência em abundância no Brasil. As folhas contêm teores elevados de óleos essenciais, flavonoides, saponinas, taninos, resinas e antocianosídeos (BASILE et al., 1990, BORGES et al., 2000). Os nomes populares da C. sylvestris são "guaçatonga", "erva-de-lagarto", "café-do-diabo" e "língua-de-teiú". Entre os componentes químicos descobertos, encontram-se o lapachol e os flavonoides (quercentina, 2-vicenina e hespertina), diterpenos (casearinas A-S, clerodanos I-VI, casearvestrinas A-
C), sesquiterpenos e ácido capriônico (BORGES et al., 2000; OBERLIES et al., 2002; TININIS et al., 2006).

As folhas da planta têm seu uso difundido na medicina popular brasileira como um antisséptico e cicatrizante em doenças de pele, e com atividade antiulcerogênica. Trabalhos mais recentes têm comprovado a sua ação como antitumoral (DE CARVALHO et al., 1998; OBERLIES et al., 2002), antibacteriano (GUTKOSKI et al., 1999), antiofídico (BORGES et al., 2000), antifúngico (OBERLIES et al., 2002) e anti-inflamatório (ESTEVES et al., 2005).

BASILE et al. (1990) investigaram a atividade preventiva antiúlcera, bem como o potencial toxicológico das folhas de guaçatonga utilizando modelo experimental de úlcera aguda induzida por estresse em ratos. Nesse trabalho, concluíram que o extrato de folhas da $\boldsymbol{C}$. sylvestris exerceu um efeito antiúlcera preventivo por meio de reduções no volume gástrico e na produção de ácido clorídrico.

$\mathrm{O}$ extrato de $\boldsymbol{C}$. sylvestris mostra-se mais potente que o misoprostol nas úlceras de moderada intensidade e equivalente ao misoprostol e à cimetidina nas lesões mais severas (BASILE et al., 1990). Nesse mesmo trabalho, não foi evidenciada toxicidade hepática, renal ou hematológica, quando administrado em doses orais cinco vezes maiores que sua $\mathrm{DE}_{50}$, durante 30 dias. $\mathrm{A} \mathrm{DL}_{50}$ estimada foi maior do que 32 vezes a $\mathrm{DE}_{50}$ empregada para a supressão da secreção ácida, mostrando elevada margem de segurança.

Publicação mais recente, empregando modelo de úlcera experimental crônica em ratos, demonstrou aumento no número de fibras colágenas após cinco dias de tratamento com o extrato de $\boldsymbol{C}$. sylvestris e 10 dias com a cimetidina, e um tempo de cicatrização duas vezes menor com o extrato de $\boldsymbol{C}$. sylvestris quando comparado com a cimetidina e o misoprostol (SERTIÉ et al., 2000).

Em trabalhos prévios, o extrato de folhas de C. sylvestris demonstrou eficácia para o tratamento (SERTIÉ et al., 2000) e a prevenção (BASILE et al., 1990; SERTIÉ et al., 2000) de úlceras induzidas experimentalmente em ratos. Isso foi observado por meio de reduções no volume de secreção gástrica e na produção de ácido clorídrico. No entanto, segundo BASILE et al. (1990), o extrato não modificou o pH da secreção gástrica. A ausência de mudança no $\mathrm{pH}$ gástrico, observada com o extrato de $\boldsymbol{C}$. sylvestris em ratos, pode ser importante para a espécie equina, pois pode não interferir no processo de digestão e absorção de proteínas da dieta e, ainda, prevenir infecções oportunistas no trato digestório (SERTIÉ et al., 2000). Em vista desses fatores, alternativas para a prevenção e o tratamento eficaz de úlceras gástricas seriam desejáveis. 
Frente a essas considerações, no que concerne à etiologia e às implicações na terapêutica da úlcera gástrica nos equinos, a $C$. sylvestris pode representar uma alternativa promissora, pois conjuga um conjunto de propriedades científicas comprovadas, dentre as quais se destacam: antiúlcera (BASILE et al., 1990; SERTIÉ et al., 2000), antibacteriana (GUTKOSKI et al., 1999) e anti-inflamatória (BORGES et al., 2000).

Não há relato, na literatura consultada, do emprego de fitoterápicos com atividade antiúlcera em equinos. A investigação de novas modalidades terapêuticas é também importante em função das poucas opções disponíveis atualmente e do custo do tratamento. Dessa maneira, o objetivo deste trabalho foi avaliar a influência do extrato de Casearia sylvestris na permeabilidade gástrica à sacarose em equinos submetidos a modelo indutor de úlcera gástrica.

\section{MATERIAL E METODOS}

Foram utilizadas folhas frescas de Casearia sylvestris Swartz coletadas no Parque Estadual "Carlos Botelho", município de São Miguel do Arcanjo, São Paulo (SP). Após a identificação da espécie pelo Instituto de Química da Universidade Estadual Paulista, campus de Araraquara, a exsicata foi depositada no herbário do Instituto Botânico do Estado de São Paulo. A secagem das folhas foi realizada em temperatura ambiente e estufa a $40^{\circ} \mathrm{C}$. Após fragmentação ${ }^{a}$, as folhas secas e moídas foram submetidas à extração com etanol anidro ${ }^{\mathrm{b}}$. $\mathrm{O}$ extrato etanólico líquido obtido foi concentrado em evaporador rotativo $^{c}$. As alíquotas do extrato concentrado foram submetidas a ensaios de perda por dessecação ${ }^{d}$. Pesagens sucessivas foram feitas até obter-se massa constante. O resíduo obtido das folhas secas foi denominado extrato seco. Para cada $100 \mathrm{~g}$ de folhas secas/moídas, foram obtidos 7,5g de extrato seco.

Foram utilizados seis equinos mestiços, três machos castrados e três fêmeas não gestantes, com idades entre dois e sete anos (mediana $=2,5$ anos), peso corporal determinado por balança analítica entre $223 \mathrm{e}$ $324 \mathrm{~kg}$ (mediana $=271 \mathrm{~kg}$ ) e distribuídos aleatoriamente em dois grupos de três animais.

Os animais foram previamente medicados com ivermectina ${ }^{\mathrm{e}}$ na dose de $0,2 \mathrm{mg} \mathrm{kg}^{-1}$ de peso corpóreo e mantidos em piquetes por, no mínimo, 30 dias antes da indução de ulceração gástrica. Durante esse período, os animais foram alimentados com dieta contendo ração comercial para equinos ${ }^{\mathrm{f}}$, na quantidade de $1 \%$ do peso corpóreo (em matéria seca), feno de Coast cross (Cynodon dactylon L. Pers.) e água ad libitum. Durante esse período, os animais foram inspecionados à distância diariamente, e os resultados do monitoramento diário e da alimentação registrados.

Durante o protocolo de indução, os animais foram submetidos a exames clínicos diários, sendo aferidas a temperatura corpórea, frequência cardíaca, frequência respiratória e motilidade intestinal. Amostras de sangue obtidas por venopunção da jugular foram coletadas no início (d0) e no término do protocolo de indução (d7) e ao término do intervalo em piquete (d39) para hemograma e determinação de sólidos totais.

Os animais foram submetidos a um protocolo de indução de úlceras gástricas durante um período sete dias: privação de alimento sólido por quatro períodos de 24 , intercalados pelo oferecimento de $1,5 \mathrm{~kg}$ de ração comercial, duas vezes ao dia por três períodos de 24h (MURRAY e EICHORN, 1996). Água à vontade foi disponibilizada durante todo o período de indução. Os animais foram submetidos a dois protocolos de indução de úlcera gástrica, cada qual seguido de intervalo de 32 dias. Nesse intervalo, foram mantidos em piquete para permitir a cicatrização das úlceras induzidas, sendo alimentados com dieta contendo ração comercial para equinos $^{\mathrm{g}}$, na quantidade de $1 \%$ do peso corpóreo (em matéria seca), feno de Coast cross (Cynodon dactylon L. Pers.) e água ad libitum. Na tarde do dia anterior ao início de cada protocolo, os animais foram colocados em baias individuais de $9 \mathrm{~m}^{2}$, recebendo a última refeição às $18 \mathrm{~h}$.

$\mathrm{O}$ experimento foi conduzido em dois períodos, utilizando delineamento cruzado (extrato versus veículo; veículo versus extrato). Em cada fase experimental, três animais foram tratados com extrato e três animais foram tratados com veículo. Os tratamentos foram administrados pela manhã via sondagem nasogástrica, uma vez ao dia, durante o período de sete dias do protocolo de indução.

$\mathrm{Na}$ ausência de dados posológicos do extrato de $\boldsymbol{C}$. sylvestris para a farmacoterapia na espécie equina, empregou-se o cálculo de extrapolação alométrica interespecífico, descrito por PACHALY e BRITO (2001), o que possibilitou o uso de dados farmacológicos obtidos em um "animal modelo". ADE empregada em ratos por BASILE et al. (1990) foi utilizada para o cálculo da dose em equinos, resultando em $9 \mathrm{mg} \mathrm{kg}^{-1}$ de peso corpóreo.

Para o tratamento-extrato, o extrato seco $\left(9 \mathrm{mg} \mathrm{kg}^{-1}\right)$ foi pesado em um gral de porcelana. Após adição de solubilizante ${ }^{\mathrm{h}}\left(80 \mu \mathrm{L} \mathrm{kg}^{-1}\right)$, ambos foram homogeneizados com pistilo. Essa mistura foi transferida para um béquer graduado e, em seguida, adicionou-se lentamente uma solução de ágar a $1 \%$ i até atingir um volume final de $4 \mathrm{~mL} \mathrm{~kg}^{-1}$ de peso corpóreo. Para o tratamento-controle (veículo), foram 
empregados o solubilizante e a solução de ágar a $1 \%$ nas doses descritas anteriormente, sem a participação do extrato em sua composição.

Imediatamente antes do início e ao final do período de restrição alimentar intermitente e ao final do período de recuperação, foi feito o teste de permeabilidade à sacarose. Para esse teste, cada animal foi posicionado em tronco de contenção e tratado com acepromazina (10mg por via intravenosa). Nas fêmeas foi conduzida lavagem do períneo com água limpa e sabão neutro e antissepsia da vulva e do períneo com iodo-povidine a $1 \%$. Nos machos, procedeu-se a higiene da extremidade distal do pênis com solução isotônica estéril. Um catéter urinário flexível para machos $^{\mathrm{j}}$ (Ø:6,6mmx137cm) ou éguas ${ }^{\mathrm{k}}$ (Ø:8,6mmx60cm) foi inserido na uretra até alcançar a bexiga. Para conferir e assegurar o máximo esvaziamento da bexiga foi feita palpação transretal da bexiga durante o procedimento de coleta de urina. Imediatamente após o esvaziamento da bexiga e a remoção do cateter urinário, os animais receberam $454 \mathrm{~g}$ de sacarose (solução a $10 \%$ em água destilada), via sonda nasogástrica ${ }^{1}$. Duas horas após a administração da sacarose, uma segunda amostra de urina foi coletada em um béquer.

Imediatamente após a coleta, o volume de cada amostra foi registrado. Após homogeneizar a urina, três alíquotas com $10 \mathrm{~mL}$ foram transferidas para tubos de polipropileno ${ }^{\mathrm{m}}$ de $15 \mathrm{~mL}$, contendo $10 \mu \mathrm{L}$ de solução de azida sódican $\left(\mathrm{NaN}_{3}\right)$, na concentração de $0,1 \mathrm{~g} \mathrm{~mL}^{-1}$. Os tubos foram tampados e guardados em um congelador a $-20^{\circ} \mathrm{C}$. A análise da urina realizada por meio da cromatografia líquida de alto desempenho e detecção amperométrica pulsátil ${ }^{\circ}$ (P.A.D.) para a determinação da concentração de sacarose foi realizada conforme descrito por O'CONNER et al. (2004).
Compararam-se os dados do exame clínico e valores hematológicos entre os animais dos grupos controle e tratamento, pelo teste t de Student. O efeito do tratamento nas concentrações de sacarose ([SAC]), no início $(\mathrm{d} 0)$ e no término $(\mathrm{d} 7)$ do protocolo de indução de úlceras e após intervalo de 32 dias (d39), foi avaliado com o teste de Wilcoxon (ROSNER, 1986). Na análise estatística, considerou-se o nível de significância de $5 \%$. Os resultados das concentrações de sacarose urinária estão expressos como mediana.

\section{RESULTADOS E DISCUSSÃO}

Com base na literatura consultada, não há nenhuma outra publicação sobre o uso da Casearia sylvestris na espécie equina. $\mathrm{O}$ efeito antiúlcera da planta tem sido investigado empregando-se ratos como modelo animal. Nesse sentido, BASILE et al. (1990) evidenciaram baixa toxicidade e ausência de ação abortiva, teratogênica, carcinogênica e mutagênica. Adicionalmente, SERTIÉ et al. (2000) não observaram alterações nos parâmetros clínico-laboratoriais associados às funções cardíacas, hepáticas, hematológicas e renais. No estudo atual, não foram observadas alterações clínicas (Tabela 1) ou nos parâmetros hematológicos e sólidos totais (Tabela 2) utilizados nos equinos após o tratamento. Entretanto, não se pode afirmar muito sobre a toxicidade em equinos devido ao número limitado de animais, ao tempo de tratamento e aos exames laboratoriais empregados no estudo atual.

O teste de permeabilidade à sacarose foi validado por O'CONNER et al. em 2004 como um indicador confiável da presença ou não de úlceras gástricas nos equinos. Em condições fisiológicas, o epitélio gástrico não é permeável à sacarose, sendo

Tabela 1 - Médias e desvios-padrão dos sinais clínicos e do peso corpóreo obtidos das avaliações clínicas conduzidas antes (d0), ao término (d7) e 32 dias após o término do protocolo de indução (d39), em animais tratados preventivamente com veículo e extrato de Casearia sylvestris.

\begin{tabular}{|c|c|c|c|c|c|c|}
\hline Grupo & Dia & $\begin{array}{l}\mathrm{FC} \\
\mathrm{bpm}\end{array}$ & $\begin{array}{c}\text { FR } \\
\mathrm{mpm}\end{array}$ & $\begin{array}{c}\text { Temperatura } \\
{ }^{\circ} \mathrm{C}\end{array}$ & $\begin{array}{l}\text { Motilidade } \\
\text { Intestinal* }\end{array}$ & $\begin{array}{c}\text { Peso } \\
\mathrm{Kg}\end{array}$ \\
\hline \multirow{3}{*}{ Extrato } & $\mathrm{d} 0$ & $32 \pm 4^{\mathrm{a}}$ & $13 \pm 2^{\mathrm{a}}$ & $37,8 \pm 0,2^{\mathrm{a}}$ & $5 \pm 2^{\mathrm{a}}$ & $264 \pm 31^{a}$ \\
\hline & $\mathrm{d} 7$ & $31 \pm 2^{\mathrm{a}}$ & $12 \pm 0^{\mathrm{a}}$ & $37,8 \pm 0,3^{\mathrm{a}}$ & $6 \pm 1^{\mathrm{a}}$ & $221 \pm 28^{a}$ \\
\hline & d39 & $31 \pm 3^{\mathrm{a}}$ & $12 \pm 2^{\mathrm{a}}$ & $37,7 \pm 0,2^{\mathrm{a}}$ & $5 \pm 1^{\mathrm{a}}$ & $278 \pm 36^{\mathrm{a}}$ \\
\hline \multirow{3}{*}{ Veículo } & $\mathrm{d} 0$ & $31 \pm 2^{\mathrm{a}}$ & $12 \pm 2^{\mathrm{a}}$ & $37,6 \pm 0,2^{\mathrm{a}}$ & $5 \pm 1^{\mathrm{a}}$ & $292 \pm 36^{a}$ \\
\hline & $\mathrm{d} 7$ & $31 \pm 5^{\mathrm{a}}$ & $12 \pm 2^{\mathrm{a}}$ & $37,8 \pm 0,3^{\mathrm{a}}$ & $5 \pm 2^{\mathrm{a}}$ & $249 \pm 36^{a}$ \\
\hline & $\mathrm{d} 39$ & $31 \pm 4^{\mathrm{a}}$ & $12 \pm 2^{\mathrm{a}}$ & $37,8 \pm 0,2^{\mathrm{a}}$ & $5 \pm 1^{\mathrm{a}}$ & $277 \pm 33^{a}$ \\
\hline
\end{tabular}

FC - frequência cardíaca; FR - frequência respiratória

*Movimento do ceco em cinco minutos. 
Tabela 2 - Médias e desvios-padrão dos componentes do eritrograma, da contagem de plaquetas, dos sólidos totais e do leucograma obtidos das amostras antes (d0), ao término (d7) e 32 dias após o término do protocolo de indução (d39), em animais tratados preventivamente com extrato de Casearia sylvestris ou veículo.

\begin{tabular}{|c|c|c|c|c|c|c|c|c|}
\hline Grupo & Dia & $\begin{array}{l}\text { Hemáceas } \\
\text { x } 10^{6} \mathrm{~mm}^{-3}\end{array}$ & $\begin{array}{c}\text { Hematócrito } \\
\%\end{array}$ & $\begin{array}{l}\text { Hemoglobina } \\
\qquad \mathrm{G} \mathrm{dl}^{-1}\end{array}$ & $\begin{array}{c}\text { VCM } \\
\text { fl }\end{array}$ & $\begin{array}{c}\mathrm{CHCM} \\
\%\end{array}$ & $\begin{array}{l}\text { Plaquetas } \\
\times 10^{3} \mu 1^{-1}\end{array}$ & $\begin{array}{c}\mathrm{ST} \\
\mathrm{G} \mathrm{dl}^{-1}\end{array}$ \\
\hline \multirow{3}{*}{ Extrato } & $\mathrm{d} 0$ & $7,3 \pm 0,53^{\mathrm{a}}$ & $34,0 \pm 3,46^{\mathrm{a}}$ & $11,6 \pm 0,6^{\mathrm{a}}$ & $46,6 \pm 1,99^{\mathrm{a}}$ & $34,3 \pm 1,73^{\mathrm{a}}$ & $307 \pm 55^{\mathrm{a}}$ & $6,9 \pm 0,8^{\mathrm{a}}$ \\
\hline & $\mathrm{d} 7$ & $7,5 \pm 0,42^{\mathrm{a}}$ & $36,0 \pm 4,36^{\mathrm{a}}$ & $11,8 \pm 1,1^{\mathrm{a}}$ & $47,6 \pm 3,22^{\mathrm{a}}$ & $32,8 \pm 0,91^{\mathrm{a}}$ & $273 \pm 110^{\mathrm{a}}$ & $7,8 \pm 0,7^{\mathrm{a}}$ \\
\hline & $\mathrm{d} 39$ & $7,5 \pm 0,57^{\mathrm{a}}$ & $33,3 \pm 2,80^{\mathrm{a}}$ & $11,5 \pm 0,5^{\mathrm{a}}$ & $44,4 \pm 1,53^{\mathrm{a}}$ & $34,6 \pm 1,54^{\mathrm{a}}$ & $250 \pm 43^{\mathrm{a}}$ & $6,8 \pm 0,8^{\mathrm{a}}$ \\
\hline \multirow{3}{*}{ Veículo } & $\mathrm{d} 0$ & $7,3 \pm 0,17^{\mathrm{a}}$ & $32,3 \pm 0,58^{\mathrm{a}}$ & $11,3 \pm 0,3^{\mathrm{a}}$ & $44,2 \pm 0,73^{\mathrm{a}}$ & $35,1 \pm 1,04^{\mathrm{a}}$ & $247 \pm 35^{\mathrm{a}}$ & $6,6 \pm 0,5^{\mathrm{a}}$ \\
\hline & $\mathrm{d} 7$ & $7,3 \pm 0,20^{\mathrm{a}}$ & $33,0 \pm 0,58^{\mathrm{a}}$ & $11,4 \pm 0,4^{\mathrm{a}}$ & $44,2 \pm 1,93^{\mathrm{a}}$ & $35,3 \pm 1,62^{\mathrm{a}}$ & $243 \pm 49^{\mathrm{a}}$ & $7,9 \pm 0,1^{\mathrm{a}}$ \\
\hline & $\mathrm{d} 39$ & $7,7 \pm 0,41^{\mathrm{a}}$ & $33,2 \pm 2,40^{\mathrm{a}}$ & $11,5 \pm 0,4^{\mathrm{a}}$ & $43,1 \pm 3,38^{\mathrm{a}}$ & $34,6 \pm 1,21^{\mathrm{a}}$ & $287 \pm 66^{\mathrm{a}}$ & $6,9 \pm 0,7^{\mathrm{a}}$ \\
\hline Grupo & Dia & $\begin{array}{l}\text { Leucócitos } \\
\times 10^{3} \mathrm{~mm}^{-3}\end{array}$ & $\begin{array}{c}\text { Bastonetes } \\
\mathrm{mm}^{-3}\end{array}$ & $\begin{array}{c}\text { Neutróf. Seg. } \\
\mathrm{mm}^{-3}\end{array}$ & $\begin{array}{c}\text { Linfócitos } \\
\mathrm{mm}^{-3}\end{array}$ & $\begin{array}{c}\text { Monócitos } \\
\mathrm{mm}^{-3}\end{array}$ & $\begin{array}{c}\text { Basófilos } \\
\mathrm{mm}^{-3}\end{array}$ & $\begin{array}{c}\text { Eosinófilos } \\
\mathrm{mm}^{-3}\end{array}$ \\
\hline \multirow{3}{*}{ Extrato } & $\mathrm{d} 0$ & $7,7 \pm 0,8^{\mathrm{a}}$ & $24,3 \pm 42,1^{\mathrm{a}}$ & $3847 \pm 806^{\mathrm{a}}$ & $3663 \pm 709^{\mathrm{a}}$ & $122 \pm 112^{\mathrm{a}}$ & $0 \pm 0^{\mathrm{a}}$ & $77 \pm 8^{\mathrm{a}}$ \\
\hline & $\mathrm{d} 7$ & $7,3 \pm 1,4^{\mathrm{a}}$ & $29,0 \pm 50,2^{\mathrm{a}}$ & $3680 \pm 646^{\mathrm{a}}$ & $3432 \pm 946^{\mathrm{a}}$ & $49 \pm 44^{\mathrm{a}}$ & $0 \pm 0^{\mathrm{a}}$ & $77 \pm 73^{\mathrm{a}}$ \\
\hline & $\mathrm{d} 39$ & $7,3 \pm 0,7^{\mathrm{a}}$ & $0,0 \pm 0,0^{\mathrm{a}}$ & $3283 \pm 623^{a}$ & $3713 \pm 957^{\mathrm{a}}$ & $62 \pm 87^{\mathrm{a}}$ & $46 \pm 53^{\mathrm{a}}$ & $147 \pm 163^{\mathrm{a}}$ \\
\hline \multirow{3}{*}{ Veículo } & $\mathrm{d} 0$ & $7,2 \pm 0,2^{\mathrm{a}}$ & $0,0 \pm 0,0^{\mathrm{a}}$ & $2942 \pm 750^{\mathrm{a}}$ & $3946 \pm 813^{a}$ & $98 \pm 113^{\mathrm{a}}$ & $25 \pm 43^{\mathrm{a}}$ & $189 \pm 217^{\mathrm{a}}$ \\
\hline & $\mathrm{d} 7$ & $6,2 \pm 0,8^{\mathrm{a}}$ & $0,0 \pm 0,0^{\mathrm{a}}$ & $3271 \pm 758^{\mathrm{a}}$ & $2800 \pm 170^{\mathrm{a}}$ & $23 \pm 40^{\mathrm{a}}$ & $65 \pm 71^{\mathrm{a}}$ & $41 \pm 70^{\mathrm{a}}$ \\
\hline & $\mathrm{d} 39$ & $7,4 \pm 0,7^{\mathrm{a}}$ & $12,2 \pm 29,8^{\mathrm{a}}$ & $3580 \pm 792^{\mathrm{a}}$ & $3639 \pm 451^{\mathrm{a}}$ & $83 \pm 86^{\mathrm{a}}$ & $11 \pm 27^{\mathrm{a}}$ & $108 \pm 51^{\mathrm{a}}$ \\
\hline
\end{tabular}

VCM - volume corpuscular médio; CHCM - concentração hemoglobina corpuscular média; ST - sólidos totais.

esta rapidamente hidrolisada no duodeno, pela ação da enzima sucrase, em suas unidades monossacarídicas, glicose e frutose. A passagem de sacarose através do epitélio gástrico para a corrente sanguínea indica lesão na mucosa gástrica. A sacarose também não é sintetizada ou hidrolisada no organismo; portanto, uma vez absorvida pela mucosa gástrica, será concentrada e excretada na urina.

$\mathrm{O}$ teste de permeabilidade à sacarose (O'CONNER et al., 2004; HEWETSON et al., 2006) foi empregado neste estudo como uma alternativa à endoscopia gástrica. O'CONNER et al. (2004) relataram uma sensibilidade e especificidade de 83 e $90 \%$, respectivamente, obtidas por meio do emprego de um ponto de corte de $7 \mathrm{mg} \mathrm{l}^{-1}$ na concentração de sacarose urinária. No delineamento deste estudo, o tratamento de animais com o veículo, além de servir como controle, foi importante para verificar a repetibilidade do teste de permeabilidade à sacarose por meio da oscilação previsível, conforme verificado em estudo de O'CONNER et al. (2004), na concentração de sacarose após o término da indução e após o intervalo em piquete de 32 dias.

A indução experimental de úlcera gástrica, semelhante a que foi preconizada por MURRAY \&
EICHORN (1996) e aos resultados obtidos no experimento de O'CONNER et al (2004), atingiu a meta proposta, provocando no tratamento-veículo um aumento sensível da permeabilidade gástrica à sacarose. Nas seis observações de animais tratados com veículo durante o protocolo de indução, a concentração de sacarose urinária foi maior $(\mathrm{P}<0,05)$ após a indução das úlceras (d7) $\left(23,4 \mathrm{mg} \mathrm{l}^{-1}\right)$, quando comparada à concentração obtida após intervalo de 32 dias em piquete (d39) $\left(3,9 \mathrm{mg} \mathrm{l}^{-1}\right)$. Houve diferença entre a concentração de sacarose urinária obtida antes $(\mathrm{d} 0)$ $\left(7,5 \mathrm{mg} \mathrm{l}^{-1}\right)$ e ao término do protoclo de indução $(\mathrm{d} 7)$ $(\mathrm{P}<0,05)$. Esses resultados indicam que ocorreu a indução de ulceração gástrica, pois conforme O'CONNER et al. (2004) a concentração obtida ao término da indução $\left(23,4 \mathrm{mg}^{-1}\right)$ é compatível endoscopicamente à presença de ulceração extensa ou úlceras multifocais que se estendem por meio da mucosa para a submucosa.

Contrariamente, nas observações dos animais tratados com extrato, não houve diferença $(\mathrm{P}>0,05)$ após a indução das úlceras $(\mathrm{d} 7)\left(11,4 \mathrm{mg} \mathrm{l}^{-1}\right)$ quando comparada à concentração obtida após intervalo de 32 dias em piquete (d39) $\left(4,4 \mathrm{mg} \mathrm{l}^{-1}\right)$. Não houve diferença entre a concentração de sacarose 
obtida antes $(\mathrm{d} 0)\left(7,8 \mathrm{mg} \mathrm{l}^{-1}\right)$ e ao término do protocolo de indução $(\mathrm{P}>0,05)$.

Da mesma forma que BASILE et al. (1990) e SERTIÉ et al. (2000), no estudo atual, objetivou-se comprovar o efeito do extrato de $\boldsymbol{C}$. sylvestris. Houve comprovação desse efeito, pois, nos equinos tratados preventivamente com o extrato, não houve diferença entre a concentração de sacarose urinária encontrada no início e no término do protocolo de indução de úlcera gástrica, ao contrário do que ocorreu com os animais tratados com veículo.

Ao término do protocolo de indução (d7), o tratamento com extrato seco de $\boldsymbol{C}$. sylvestris resultou em diminuição significativa $(\mathrm{P} \leq 0,05)$ na concentração de sacarose urinária $\left(11,4 \mathrm{mg} \mathrm{l}^{-1}\right)$ quando comparado ao veículo (23,4mg $\left.{ }^{-1}\right)$ (Figura 1). No presente estudo, a comparação da concentração de sacarose entre os tratamentos com extrato e veículo e a ausência de efeitos colaterais nos parâmetros clínico-hematológicos observados permitem vislumbrar a possibilidade do emprego clínico do extrato de $\boldsymbol{C}$. sylvestris na prevenção de úlceras gástricas em equinos. É importante frisar que o efeito antiúlcera observado sugere apenas uma tendência do extrato à proteção gástrica. Apesar da diferença significativa observada ao término do protocolo de indução entre o extrato e o veículo, a concentração de sacarose urinária dos animais tratados com extrato ficou acima do ponto de corte de $7 \mathrm{mg} \mathrm{l}^{-1}$, estabelecido por O'CONNER et al. (2004). Nesse contexto, a endoscopia gástrica, não disponível no momento da condução dos experimentos, poderia corroborar os achados do teste de permeabilidade.

A maioria dos pesquisadores aventa a hipótese de que a atividade antiúlcera comprovada de certas plantas medicinais tem origem na modulação de fatores de defesa por meio de mecanismos de citoproteção. Esse efeito, geralmente, não é relacionado a mudanças no pH (SERTIÉ et al., 2000). Estudos recentes têm demonstrado que diferentes substâncias oriundas de plantas não somente conferem citoproteção, como também aceleram a cicatrização. Essas substâncias podem também possuir ação antiinflamatória, promovendo reparo tecidual por meio da expressão de diversos fatores de crescimento celular, exibindo atividade antioxidante e atividade anticarcinogênica (ZAYACHKIVSKA et al., 2005). Esses fatores parecem ser mais relevantes para a cicatrização de úlceras presentes na mucosa glandular dos equinos, frequentemente causadas pela administração de antiinflamatórios não esteroidais. Tendo em vista o efeito citoprotetor do extrato, seria interessante averiguar o comportamento das úlceras nesse tipo de modelo.

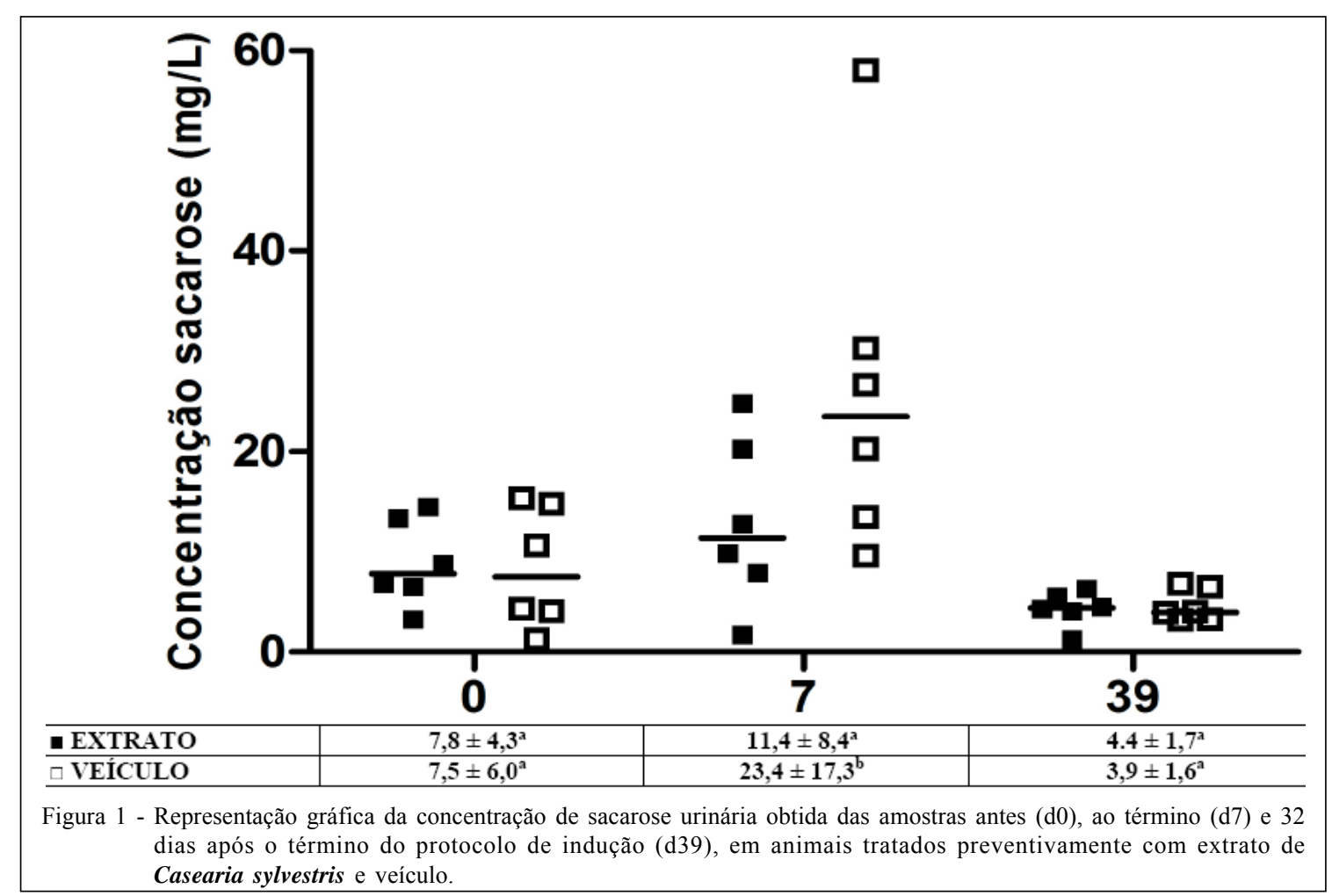

Ciência Rural, v.40, n.2, fev, 2010. 


\section{CONCLUSÃO}

Na presença do extrato de $\boldsymbol{C}$. sylvestris ou do veículo, a permeabilidade gástrica à sacarose foi de intensidade diferente, em que se evidenciou que o tratamento com extrato de C. sylvestris evitou o aumento da concentração de sacarose quando comparado ao veículo. Estudos subsequentes deverão ser realizados com o objetivo de comprovar ou não o efeito da $\boldsymbol{C}$. sylvestris na prevenção e no tratamento de úlceras espontâneas.

\section{COMITÊ DE ÉTICA E BEM ESTAR}

O presente trabalho, registrado na Comissão de Ética e Bem-Estar Animal da Faculdade de Ciências Agrárias e Veterinárias da Universidade Estadual Paulista (UNESP), Campus de Jaboticabal, Jaboticabal - SP, sob o número 006324, cumpriu todas as exigências em relação ao bem-estar animal, sendo executado conforme as normas do COBEA (Comitê Brasileiro de Experimentação Animal, lei n. 6.638 de 8 de maio de 1979).

\section{AGRADECIMENTO}

Ao Instituto de Química, Universidade Estadual Paulista (UNESP), Araçatuba, e ao Gastrointestinal Laboratory, Texas A\&M University, College Station, Texas.

\section{FONTES DE AQUISIÇÃO}

a - Moinho MA-680. Marconi Equipamentos Laboratório Piracicaba - SP.

b - Etanol anidro. Merck - Alemanha.

c - Evaporador rotativo R-114 RE e B-480. Büchi Labortechnik - Suíça.

d - Dessecador MA-184 e V-500. Marconi Equipamentos Laboratório - Piracicaba - SP.

e - Eqvalan Pasta - Merial Saúde Animal Ltda - Paulínia - SP

f - Ração para Equinos Classic Horse - Fri-Ribe - Pitangueiras - SP

g - Ração para Equinos Classic Horse - Fri-Ribe - Pitangueiras - SP

h - Tween 80 P.S. (polissorbato). Acros Organics - New Jersey

- USA.

i - Agar bacteriológico. Acros Organics - New Jersey - USA.

j - Stallion urinary catheter J 90S. Jorgensen Laboratories -

Colorado - USA.

k - Mare urinary catheter J 90SM. Jorgensen Laboratories Colorado - USA.

1 - Medium PVC stomach tube. J106 ME. Jorgensen Laboratories - Colorado - USA.

m - Corning centrifuge tubes $15 \mathrm{ml}$. CLS430791. Corning ${ }^{\circledR}$ Corning Glass Works - New York - U.S.A.

n - Azida sódica - Acros Organics - New Jersey - U.S.A.

o - ED40 Electrochemical Detector; Dionex Corporation, Sunnyvale, California.

\section{REFERÊNCIAS}

ANDREWS, F.M. et al. Recommendations for the diagnosis and treatment of equine gastric ulcer syndrome (EGUS). Tutorial Article. Equine Veterinary Education, Lexington, v.1, n.2, p.122-134, 1999.
BASILE, A.C. et al. Pharmacological assay of Casearia sylvestris. I: Preventive anti-ulcer activity and toxicity of the leaf crude extract. Journal of Ethnopharmacology, Limerick, v.30, n.1, p.185-197, 1990. Disponível em: <http://www.sciencedirect.com/ science?_ob=ArticleURL\&_udi=B6T8D-478BPN4$7 \&$ _user $=687358 \&$ \&rdoc $=1 \&$ fmt $=\&$ \&orig $=$ search \&_sort $=\mathrm{d} \&$ docanchor $=\&$ view $=$ c\&_acct $=\overline{\mathrm{C}} 00003 \overline{7} 899 \&$ \& version $=1 \&$ urlV ersion $=0 \&$ userid $=687358 \& \mathrm{md} 5=58 \mathrm{c} 29$ ade 93032 eacfl $164 \mathrm{~d} 4 \mathrm{~cd} 147 \mathrm{db} 799>$. Acesso em: 13 nov. 2009. doi: 10.1016/0378-8741(90)90007-G.

BORGES, M.H. et al. Effects of aqueous extract of Casearia sylvestris (Flacourtiaceae) on actions of snake and bee venoms and on activity of phospholipases $A_{2}$. Comparative Biochemistry and Physiology - Part B, Oxford, v.127, n.1, p.21-30, 2000. Disponível em: <http://www.sciencedirect.com/ science?_ob=ArticleURL\&_udi=B6T2R-4164V0D$3 \&$ _user $=\overline{6} 87358 \&$ rdoc $=1 \&$ fmt $=\&$ \&orig $=$ search \&_sort $=\mathrm{d}$ 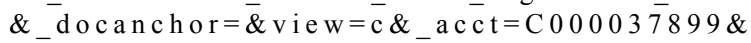 _version $=1 \&$ \& urlVersion $=0 \&$ \& userid $=687358 \&$ $\overline{\mathrm{md}} 5=628 \mathrm{~b} 349 \mathrm{~b} 8 \mathrm{f} 83 \mathrm{~d} 9 \mathrm{c} 065 \mathrm{f} 400138 \mathrm{e} 50 \overline{2} 9 \mathrm{~d} 7>$. Acesso em: 13 nov. 2009. doi: 10.1016/S0305-0491(00)00237-6.

DE CARVALHO, P.R.F. et al. Acetylated dna-damaging clerodane diterpenes from Casearia sylvestris. Phytochemistry, New York, v.48, n.6, p.1.695-1.662, 1998. Disponível em: <http:// www.sciencedirect.com/science?_ob=ArticleURL\&_udi=B6TH744D42G6-Y\&_user $=687358 \&$ \&doc $=1 \&$ fmt $=\&$ \& orig $=$ search $\&$ _sort $=\mathrm{d} \&$ _docanchor $=\& \mathrm{view}=\mathrm{c} \&$ _acct $=\overline{\mathrm{C}} 0000$ $37899 \&$ \& version $=1 \&$ \&_urlversion $=0 \&$ \&_userid $=6$ $87358 \& \mathrm{md} 5=8 \mathrm{dec} 3 \mathrm{ba} 661 \mathrm{aa} 65 \mathrm{f} 6 \mathrm{a} 65 \mathrm{ea} 89 \mathrm{cdc} 9892 \mathrm{a} 2>$. Acesso em: 13 nov. 2009. doi: 10.1016/S0031-9422(98)00249-0.

ESTEVES, I. et al. Gastric antiulcer and anti-inflammatory activities of the essential oil from Casearia sylvestris Sw. Journal of Ethnopharmacology, Limerick, v.101, n.1, p.191196, 2005. Disponível em: <http://www.sciencedirect.com/ science?_ob=ArticleURL\&_udi=B6T8D-4GHSGMF$2 \&$ \&user $=687358 \&$ \&doc $=1 \&$ \&mt $=\&$ \&_orig $=\mathrm{search}$ \&_sort $=$ d\&_docanchor $=\&$ view $=$ c \&_acct $=$ C000037899

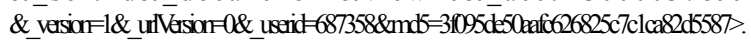
Acesso em: 13 nov. 2009. doi: 10.1016/j.jep.2005.04.020.

GUTKOSKI, S.B. et al. Atividade antibacteriana in vitro do decocto de Casearia sylvestris sobre agentes de interesse em saúde animal e saúde coletiva. In: CONGRESSO ESTADUAL DE MEDICINA VETERINÁRIA, 14., 1999, Gramado, RS. Anais... Gramado: SOVERGS, 1999. p.315.

HEWETSON, M. et al. Sucrose concentration in blood: a new method for assessment of gastric permeability in horses with gastric ulceration. Journal of Veterinary Internal Medicine, Lakewood, v.20, n.2, p.388-394, 2006. Disponível em: <http:/ /www3.interscience.wiley.com/cgi-bin/fulltext/120715301/ PDFSTART $>$. Acesso em: 13 nov. 2009. doi: 10.1111/j.19391676.2006.tb02873.x.

McCLURE, S.R. et al. Prevalence of gastric ulcers in show horses. Journal of the American Veterinary Medical Association, Schaumburg, v.215, n.8, p.1130-1133, 1999.

McLOUGHLIN, R.M. et al. Erradication of Helicobacter pylori: recent advances in treatment. Fundamental and Clinical Pharmacogy, Oxford, v.19, n.4, p.421-427, 2005. Disponível em: <http://www3.interscience.wiley.com/cgi-bin/fulltext/ 118700218/PDFSTART>. Acesso em: 13 nov. 2009. doi: 10.1111/j.1472-8206.2005.00340.x. 
MURRAY, M.J.; EICHORN, E.S. Effects of intermittent feed deprivation, intermittent feed deprivation with ranitidine administration, and stall confinement with ad libitum access to hay on gastric ulceration in horses. American Journal of Veterinary Research, Schaumburg, v.57, n.11, p.1599-1603, 1996.

MURRAY, M.J. et al. Prevalence of gastric lesions in foals without signs of gastric disease: an endoscopic survey. Equine Veterinary Journal, Suffolk, v.22, n.1, p.6-8, 1990.

MURRAY, M.J. et al. Factors associated with gastric lesions in Thoroughbred racehorses. Equine Veterinary Journal, Suffolk, v.28, n.5, p.368-374, 1996.

OBERLIES, N.H. et al. Novel bioactive clerodane diterpenoids from the leaves and twigs of Casearia sylvestris. Journal of Natural Products, Cincinnati, v.65, n.2, p.95-99, 2002. Disponível em: <http://pubs.acs.org/doi/abs/10.1021/np010459m>. Acesso em: 13 nov. 2009. doi: 10.1021/np010459m

O'CONNER, M.S. et al. Evaluation of urine sucrose concentration for detection of gastric ulcers in horses. American Journal of Veterinary Research, Schaumburg, v.65, n.1, p.31-39, 2004. Disponível em: <http:// avmajournals.avma.org/doi/abs/10.2460/ajvr.2004.65.31>. Acesso em: 13 nov. 2009. doi: 10.2460/ajvr.2004.65.31.

PACHALY, J.R.; BRITO, H.F.V. Interspecific allometric scaling. In: FOWLER, M.E.; CUBAS, P.R. Biology, medicine and surgery of South American wild animals. Ames: Iowa University, 2001. p.475-481.

RAGHUNATH, A.S. et al. Review article: the long-term use of proton-pump inhibitors. Alimentary Pharmacology and Therapeutics, Oxford, v.22, supl.1, p.55-63, 2005. Disponível em: <http://www3.interscience.wiley.com/journal/118696795/ abstract>. Acesso em: 13 nov. 2009. doi: 10.1111/j.13652036.2005.02611.x.
ROSNER, B. Nonparametric methods. In: PAYNE, M. Fundamentals of biostatistics. Boston: Duxbury, 1986. p. 278-301

SCOTT, D.R. et al. Evidence of helicobacter infection in the horse. In: AMERICAN SOCIETY FOR MICROBIOLOGY (GENERAL MEETING), 101., 2001, Orlando. Proceedings... Orlando: ASM Abstract Database, 2001. p.287.

SCOTT, D.R. et al. A longitudinal sero-epidemiological study of helicobacter infection in the horse. In: AMERICAN SOCIETY FOR MICROBIOLOGY (GENERAL MEETING), 103., 2003, Washington. Proceedings... Washington: ASM Abstract Database, 2003. p.201.

SERTIÉ, J.A.A. et al. Antiulcer activity of the crude extract from the leaves of Casearia sylvestris. Pharmaceutical Biology, Holanda, v.38, n.2, p.112-119, 2000. Disponível em: <http:// www.informaworld.com $/ \mathrm{smpp} /$ content $\sim \mathrm{db}=$ all? content $=10.1076$ / 1388-0209\%28200004\%2938:2;1-1;FT112>. Acesso em: 13 nov. 2009. doi: 10.1076/1388-0209(200004)38:2;1-1;FT112.

TININIS, A.G. et al. Composição e variabilidade química de óleo essencial de Casearia sylvestris SW. Revista Brasileira de Plantas Medicinais, Botucatu, v.8, n.4, p.132-136, 2006.

ZAVROS, Y. et al. Hypergastrinemia in response to gastric inflammation suppresses somatostatin. American Journal of Physiology Gastrointestinal and Liver Physiology, Bethesda, v.282, n.1, p.175-183, 2002. Disponível em: $<$ http:/ /ajpgi.physiology.org/cgi/reprint/282/1/G175>. Acesso em: 13 nov. 2009. doi: 10.1152/ajpgi.00287.2001.

ZAYACHKIVSKA, O.S. et al. Gastroprotective effects of flavonoids in plant extracts. Canadian Journal of Physiology and Pharmacology, Ottawa, v.56, supl.1, p.219231, 2005 